\title{
Guillermo 0’Donnell y su aporte al desarrollo de la democracia en América Latina desde la tercera ola de democratización*
}

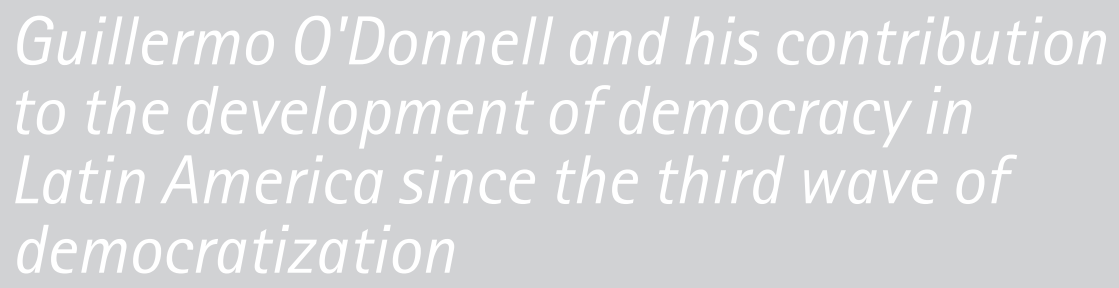

\section{Hernán Pablo Toppi**}

\begin{abstract}
RESUMEN
Guillermo O'Donnell ha sido un teórico de la democracia. Su investigación se ha vuelto indispensable a la hora del estudio de la democracia en América Latina. Demostró las particularidades de las democracias de la región y las limitaciones que las definiciones tradicionales tenian para ello. Este estudio analiza libros y ensayos seleccionados de O'Donnell provenientes de la etapa que se inició con la tercera ola de democratización y se extendió hasta la última agenda de investigación encarada por el autor. Buscaremos identificar no sólo los puntos principales de su teoría, sino también los desafíos que se desprendieron de ella para el desarrollo de las democracias emergentes: de lo macro a lo micro, de la primera a la segunda transición, del régimen al Estado democrático.
\end{abstract}

\section{PALABRAS CLAVE}

Guillermo O'Donnell, teoría, democracia, América Latina, desafíos.

\begin{abstract}
Guillermo O'Donnell has been a Theoretician of Democracy. His research has become indispensable at the time of the study of democracy in Latin America. He demonstrated the particularities of the region's democracies and the limitations that traditional definitions had for it. This study analyzes selected books and essays by O'Donnell from the stage that began with the third wave of Democratization and extended to the last research agenda addressed by the author. We will seek to identify not only the main points of his theory, but also the challenges that emerged from it for the development of Emerging Democracies: from the macro to the micro, from the first to the second transition from the Regime to the Democratic State.
\end{abstract}

\section{KEYWORDS}

Guillermo O'Donnell, theory, democracy, Latin America, challenges.

\footnotetext{
*Artículo recibido el 6 de septiembre de 2017 y aceptado para su publicación el 4 de diciembre de 2017

** Universidad de Buenos Aires (UBA); Consejo Nacional de Investigaciones Científicas y Técnicas Conicet (hernantoppi@gmail.com; htoppi@sociales.uba.ar) ORCID: 0000-0002-8948-6961
} 
SUM ARIO

1. Introducción

2. Definiciones tradicionales de democracia: realistas pero con limitaciones

3. Primer desafío: de lo macro a lo micro

4. Segundo desafío: de la primera a la segunda transición

5. Tercer desafío: del régimen al Estado democrático

6. Conclusiones: el legado de Guillermo O'Donnell

"Los valores determinan las preguntas de investigación, es decir, las preguntas surgen desde sus preocupaciones morales y su compromiso politico. En este sentido, yo soy weberiano. He hecho investigaciones sobre preguntas originadas en el hecho de que teniamos regimenes horribles en América Latina, y porque yo prefería por mucho a la democracia. Mis preguntas todavia provienen de amplias inquietudes politicas y morales".

Guillermo O'Donnell en entrevista con Gerardo Munck. "Democratización, compromiso político y diseño de investigación”.

\section{INTRODUCCIÓN}

El pensamiento de Guillermo 0’Donnell y la historia democrática en América Latina han estado estrechamente conectados. Este trabajo busca analizar una de las aristas que surgen de dicha relación: los aportes teóricos que el primero brindó durante y con posterioridad a la tercera ola de democratización. Su notoriedad y relevancia está en el doble impacto que tuvieron desde entonces. Por un lado, muchas veces dieron cuenta de las limitaciones que las conceptualizaciones tradicionales de democracia tenían a la hora de estudiarla en los países que recientemente habían atravesado un proceso de reinstauración de gobiernos electos popularmente. Por otro, evidenciaron e instalaron en la agenda de investigación problemáticas que se transformarian en desafíos que debían enfrentarse en pos de evitar las regresiones autoritarias del pasado y, al mismo tiempo, instaurar democracias representativas sustentables.

Lo anterior impulsa al estudio analítico de la obra de Guillermo 0’Donnell que se propone en estas páginas y que estará centrado en tres líneas de 
discusión: la cultura democrática, el régimen democrático y el Estado democrático. Éstas darán cuenta del aporte teórico del autor, a partir del análisis de obras seleccionadas que este último ofreció tanto a la comunidad académica como a la sociedad, y que en las últimas cuatro décadas han influenciado en el modo de estudiar, evaluar y etiquetar conceptualmente a las democracias latinoamericanas. La relevancia de estudiar estas tres aristas se encuentra en que forman parte de un esfuerzo teórico y conceptual clave para el entendimiento del funcionamiento democrático de la región en el pasado y en la actualidad, y que, además, ha permitido identificar áreas de debilidad en pos de la generación de mejores democracias. Frente a esto, podemos decir que 0'Donnell planteó en su obra una serie de desafíos en la región de cara al establecimiento de democracias duraderas, los cuales serán analizados en estas páginas.

El trabajo continuará de la siguiente manera. Inicialmente, proponemos una breve consideración de las definiciones de democracia consideradas por 0'Donnell como realistas, pero con limitaciones para el estudio de América Latina. Posteriormente, nos abocaremos al análisis de cada una de las tres líneas de discusión (los desafíos). Finalmente, expondremos las conclusiones del estudio.

\section{Definiciones tradicionales de Democracia: Realistas Pero con limitaciones}

El estudio de la democracia precede a Guillermo 0'Donnell. Al momento de la aparición de la obra de este autor, ya se encontraban presentes en la academia diversas alternativas a la hora de conceptualizar a la democracia. Debido a la aceptación con la que contaban, pasaron a ser las más citadas a la hora de estudiar la temática a nivel mundial. Sin embargo, las nuevas democracias resultantes manifestaron características no siempre cubiertas o consideradas por dichas definiciones, lo que generaba un vacío. Esto no significaba para 0'Donnell que todas las definiciones fueran incorrectas. Muchas de ellas fueron consideradas por él como realistas, es decir, como definiciones que enunciaban atributos cuya presencia o ausencia podía ser verificada empíricamente y que tendían a incluir dos grandes aspectos: las elecciones limpias y las libertades concomitantes que debían encontrarse en escenarios donde la democracia perdurase y que no implicase un hecho aislado. ${ }^{1}$

Entre las diferentes definiciones de democracia consideradas como realistas por nuestro autor de referencia, están las de Joseph Schumpeter, Adam Przeworski y Robert Dahl. El primero definió a la democracia como un arreglo

\footnotetext{
' O'Donnell, Guillermo, Disonancias. Críticas democráticas a la democracia, Buenos Aires, Prometeo, 2007, p. 30.
} 
institucional para arribar a decisiones políticas, legislativas y administrativas, donde aquellos que adquieren el poder lo hacen mediante la lucha competitiva por los votos. ${ }^{2}$ Por su parte, Przeworski describió a la democracia como un sistema donde hay un marco de competencia que implica no sólo que los partidos pierden elecciones y hay alternancia, sino que también hay incertidumbre sobre el resultado electoral y aquellos que ganan la elección deben poder asumir sus cargos. ${ }^{3}$ Robert Dahl acuñó el término de poliarquía para hacer referencia de un tipo de régimen que (en tanto representativo y pluralista) les otorga a los individuos adultos la ciudadanía política. Ésta es la que les permite tener el derecho de, si así lo creen necesario, oponerse al mandatario de turno y votar por otros candidatos provenientes de la oposición. ${ }^{4}$

Como puede entenderse, una definición realista a partir del cotejo empírico de sus dimensiones y atributos nos permite diferenciar a los países democráticos de aquellos que no lo son. No obstante, las definiciones tradicionales y realistas provenían de países con una larga historia democrática detrás. Estas conceptualizaciones fueron utilizadas para el estudio de las nuevas democracias. Guillermo 0’Donnell coincidió con ellas en la importancia de una cultura democrática para el fortalecimiento del régimen en este nuevo contexto emergente. Sin embargo y de manera paralela, estas conceptualizaciones podían no contemplar situaciones o características relevantes de los escenarios novedosos, los cuales requerirían de una refinada conceptualización para que la teoría democrática pudiese ofrecer un correcto alcance comparativo.

Ya que muchas de las nuevas democracias parecían ser de una clase diferente, surgió la necesidad de una teoría que las describiera y las explicara. Fueron dos las razones que impulsarían esta acción, de acuerdo con Guillermo 0’Donnell. Primero, porque una teoría de la democracia debía abarcar a todos los tipos existentes. Segundo, porque sus efectos podían ser diferentes. ${ }^{5}$ Será esto entonces lo que motorice los esfuerzos conceptuales que nosotros presentaremos como parte del segundo y tercer desafío, de cara a la construcción de mejores democracias.

\section{Primer desafí: De lo macro a lo micro}

\footnotetext{
${ }^{2}$ Schumpeter, JosePH, Capitalism, Socialism, and Democracy, Nueva York, Harper, 1975, p. 242.

3 Przeworski, Adam, Democracy and the Market. Political and Economic Reforms in Eastern Europe and Latin America, Nueva York, Cambridge University Press, 1991, p. 10.

${ }^{4}$ DaHL, RoBert, La democracia y sus críticos, Paidós, Buenos Aires, 1992, p. 266.

${ }^{5}$ O'Donnell, Guilermo, "Acerca del estado, la democratización y algunos problemas conceptuales. Una perspectiva latinoamericana con referencias a paises poscomunistas", en Guillermo O'Donnell, Contrapuntos. Ensayos sobre autoritarismo y democratización, Buenos Aires, Legislatura Porteña de la Ciudad de Buenos Aires, 2014, p. 235.
} 
El primer desafío se enmarca en un periodo en el cual imperaba la incertidumbre sobre el futuro democrático. La sensación era que la posible salida del autoritarismo, que experimentaban los países de América Latina en los años ochenta, no implicaba automáticamente la llegada de una democracia; de hacerlo, nada aseguraba su perdurabilidad en el tiempo. Ambas cuestiones dependerían de las condiciones en las que se llevase a cabo el proceso transicional y de las predisposiciones que los diferentes actores (políticos y civiles) tuviesen frente a la práctica democrática. Esto significaba que, para la instauración y supervivencia de la democracia, no sería suficiente el proceso de negociación entre la elite del antiguo régimen y la clase política, sino que la ciudadanía también tendría un rol fundamental para alcanzar dicho resultado a partir del modo en que se vincula con las instituciones democráticas y con los demás sujetos. Así la incertidumbre convivió en el pensamiento de 0’Donnell con la esperanza de la generación de las condiciones propicias para la llegada de la democracia. El desafío pasaba entonces por ir de lo macro a lo micro, construyendo un escenario alejado del autoritarismo.

Comencemos por lo macro, pues toda transición se inicia mediante una liberalización encausada desde las esferas de poder. Esto es lo que indicó Guillermo 0'Donnell junto con Philippe Schmitter en el famoso "libro verde" que en español llevó el título de Transiciones desde un gobierno autoritario. Conclusiones tentativas sobre las democracias inciertas. ${ }^{6}$ En línea con la incertidumbre que arriba mencionábamos, los autores argumentaron que el proceso transicional que da inicio a la salida del autoritarismo podía terminar en una democracia o no hacerlo. En otras palabras, nada garantizaba que al final del camino se encontrase una democracia, ya que una transición es el paso de un régimen político a otro (no necesariamente una democracia).

Si la transición implica salir de un autoritarismo, la primera se inicia con una liberalización que conlleva la reinstauración de determinados derechos que los gobernantes ya no podrían continuar infringiendo y que, por ende, se transformarían en una salvaguarda para los individuos comunes y corrientes. Es importante destacar que 0'Donnell y Schmitter en esta etapa no hablan de ciudadanía (es decir, la liberalización no garantiza la existencia de una ciudadanía) pues ésta última recién aparecería con la democratización, momento diferente y posterior al de la liberalización. Es diferente ya que la democratización no involucra únicamente la existencia de derechos, sino también el

\footnotetext{
${ }^{6}$ O'Donnell, Guillermo y Schmitter, Philippe, Transiciones desde un gobierno autoritario. Conclusiones tentativas sobre las democracias inciertas, Buenos Aires, Prometeo, 2010.
} 
reconocimiento de que los individuos, ahora sí considerados como ciudadanos, tienen capacidad de formular decisiones colectivas que puedan ser respetadas por el conjunto de los actores con los cuales conviven.

Al dividir liberalización y democratización, O’Donnell y Schmitter no sólo destacan que son momentos diferentes, sino que además puede darse la primera sin la segunda (mediante la instauración de una pseudodemocracia) lo cual es parte de la incertidumbre propia del proceso de transición. Ahora bien, puede haber liberalización sin democratización, pero no democratización sin liberalización, ya que en este momento inaugural es cuando los líderes del régimen autoritario le regresan a la población los derechos cercenados en el pasado. Lo anterior termina demostrando su importancia, pues la activación de derechos individuales y colectivos precede a la realización de elecciones limpias. ${ }^{7}$

La incertidumbre, en el resultado final en la transición, se encuentra favorecida además por la ausencia de reglas preestablecidas que encaminen dicho proceso de una manera institucionalizada. Se puede tener éxito o fracasar en este “ajedrez de múltiples tableros”, concebido por 0’Donnell y Schmitter para describir el proceso transicional donde diversos actores juegan e interactúan en más de un escenario de negociación. De este modo, los autores precisan que lo que guiará el proceso transicional no serán reglas, sino el poder relativo y las estrategias de negociación llevadas a cabo por los actores (los pertenecientes al régimen saliente y la clase política).

Ahora, si bien no se puede predecir a ciencia cierta el resultado final, la negociación a la que se hace referencia es esperable que suceda, pues los regímenes autoritarios han tendido a presentarse como transitorios, en el sentido de que "son regímenes que practican la dictadura y la represión en el presente a la par que prometen la democracia y la libertad para el futuro". ${ }^{8}$

La negociación es esperable que suceda también por las características de la coalición gobernante en los regímenes autoritarios. Guillermo 0’Donnell y Philippe Schmitter plantearon que dentro de la coalición autoritaria existen dos grupos diferenciados: los duros y los blandos. Mientras que los primeros pretenden la continuidad del régimen autoritario, los segundos manifiestan la necesidad de la apertura en pos de generar canales de legitimación electoral, por lo que son afines a la activación del proceso de liberalización. Es aquí donde encontramos un primer escenario, donde el poder relativo de los actores toma peso,

\footnotetext{
${ }^{7}$ O'Donnell, Guillermo y Schmitter, Phillppe, Transiciones desde un gobierno autoritario. Conclusiones tentativas sobre las democracias inciertas, Buenos Aires, Prometeo, 2010, p. 33.

${ }^{8}$ O'Donnell, Guillermo y Schmitter, Phillppe, Transiciones desde un gobierno autoritario. Conclusiones tentativas sobre las democracias inciertas, Buenos Aires, Prometeo, 2010, p. 41.
} 
ya que los duros no permitirian una transición en la medida de que el régimen autoritario (y por ende ellos mismos) mantenga una cuota de poder relevante.

En cambio, en escenarios de crisis y debilidad del régimen autoritario, son los blandos los que encontrarian las condiciones para impulsar la conformación de la "coalición liberalizante" con los sectores políticos democráticos mediante la cual se activaría la transición. ${ }^{9}$ En este escenario alternativo, también entra en juego el poder relativo de los actores (ahora los blandos y la clase política), ya que ambos buscarán tener un control estratégico del proceso transicional y alcanzar el mejor acuerdo para su sector a partir de los pactos que surjan de la negociación. De este modo, de contar los blandos con mayor poder tendrán mayores oportunidades de imponer una transición tutelada (como fue el caso chileno). Dicha situación es difícil de alcanzar ante un elevado nivel de descredito del régimen en retirada que les impida imponer condiciones en el camino hacia las elecciones competitivas (como fue el caso argentino).

Si el camino hacia una democracia es complejo e incierto a nivel macro, no menos difícil es la situación a nivel micro, es decir, en la esfera relacionada con la vida cotidiana de los individuos. Una de las grandes lecciones que ha legado la literatura de Guillermo 0'Donnell es que ambos niveles (el macro y el micro) implican diversos desafíos para la instauración y supervivencia de una democracia. Con esto quedaba en evidencia que no sólo aquellos que participaban en las esferas del poder político tenían un rol en este proceso, sino también las personas comunes y corrientes que interactuaban cotidianamente a nivel de la sociedad. Todos, unos y otros, contaban con un rol determinante en este camino, cuyo mejor escenario sería llegar a una democracia. Es por ello que la atención no debía centrarse únicamente en lo sucedido a nivel macro, pues sin un escenario favorable en lo micro, la democracia continuaría pendiendo de un hilo considerablemente débil.

La realidad encontrada en lo micro no escapaba al contexto general en el cual se circunscribió el análisis, es decir, el de la presencia de autoritarismos que hasta entonces se habían impuesto sobre gobiernos democráticos inestables. Estos contextos estaban relacionados con la supresión de la ciudadanía y el silenciamiento político del sector popular; por tanto, respondían a escenarios donde "a lo mejor que se puede aspirar es al 'consenso tácito'. Es decir, despolitización, apatía y refugio en una cotidianidad altamente privatizada. Y

\footnotetext{
${ }^{9}$ O'Donnell, Guillermo, "Notas para el estudio de procesos de democratización política a partir del Estado burocrático-autoritario", Guillermo O'Donnell, Contrapuntos. Ensayos sobre autoritarismo y democratización, Buenos Aires, Legislatura Porteña de la Ciudad de Buenos Aires, 2014, p. 196.
} 
al miedo". ${ }^{10}$ Como vemos, para 0’Donnell el autoritarismo tenía la capacidad de expandirse a los diferentes ámbitos de la vida en sociedad. En el ensayo “ ¿Y a mí, qué mierda me importa? Notas sobre sociabilidad y política en la Argentina y Brasil" es donde esto último queda claro.

Comparando a la sociedad argentina y brasileña, 0’Donnell argumentó que la sociedad argentina, si bien era más igualitaria que la segunda, también era más autoritaria. Este hecho no era independiente del impacto que a nivel social había tenido el régimen autoritario vigente en la Argentina desde 1976, mediante una brutalidad que no sólo había incentivado el miedo sino también el distanciamiento entre los sujetos, corporaciones y organizaciones de la sociedad civil, las cuales estaban más interesadas en sí mismas que en el colectivo social. Así, el régimen autoritario moldeó una sociedad sometida, individualista, clandestina, pero también autoritaria, pues entre los actores y organizaciones civiles se extendió el despotismo imperante. El autor lo presenta así en Democracia en Argentina. Micro y macro: "No es fácil ni simpático hacer este planteo, pero me parece que la cuestión de la democracia - en la Argentina, como en todo caso en el que se han cometido atrocidades semejantes- también pasa por el doloroso momento de reconocer que no hubo sólo un gobierno brutalmente despótico, sino también una sociedad que durante esos años fue mucho más autoritaria y represiva que nunca $-\mathrm{y}$ que no fueron pocos los que determinaron que así sucediera-". ${ }^{11}$

El diagnóstico crítico que Guillermo 0’Donnell estaba planteando tenía un elemento adicional y no menos importante. La existencia de una sociedad que, en tanto individualista y corporativa, carecería de los incentivos para la generación de una sociedad política democrática. La democracia no podía funcionar ni sobrevivir. Ahora bien, O'Donnell fue claro en lo siguiente. Reconocer este problema existente en lo micro posibilitaría el necesario planteamiento de su resolución, hecho que de otra manera continuaría postergado. La identificación de estas prácticas ajenas a una cultura política democrática en lo micro permitía evidenciar la relevancia que las voces críticas (pero acalladas en el pasado) tenían, no sólo en la arena política, sino también en la social, pues en ambos niveles las expresiones autoritarias debían ser removidas.

El desafío se encontraba, entonces, en generar las condiciones para desactivar el autoritarismo en ambos niveles, en lo macro y en lo micro, ya que

\footnotetext{
${ }^{10}$ O'Donnell, Guillermo, "Tensiones en el Estado burocrático-autoritario y la cuestión de la democracia", en Guillermo O'Donnell, Catacumbas, Buenos Aires, Prometeo, 2008, p. 78.

"O'Donnell, Guillermo, "Democracia en la Argentina. Micro y macro", en Guillermo O'Donnell, Contrapuntos. Ensayos sobre autoritarismo y democratización, Buenos Aires, Legislatura Porteña de la Ciudad de Buenos Aires, 2014, p. 117.
} 
enfocarse únicamente en el nivel macro no favorecería la instauración de una democracia duradera. Esta situación había sido cotidiana en la historia de varios países de América Latina. En otros términos, "la única manera de avanzar en el proceso de construcción democrática es practicando la democracia en el terreno político y - por lo menos- combatiendo las pautas de autoridad despóticas en todos los demás”. ${ }^{12}$

\section{Segundo desafío: de la primera a la Segunda transición}

En la agenda de investigación de Guillermo 0’Donnell, el contexto político existente ha tenido un rol importante. Por un lado, porque le ayudó a delinear la temática de investigación. Por otro, porque el autor le asignó un rol en su teorización en términos de los resultados esperados de su análisis. En la sección pasada, vimos en acción ambos aspectos, y lo mismo ocurre aquí. Transcurrida la década del ochenta, la democracia en gran parte de América Latina se fortalecía, la posibilidad de regresión autoritaria perdía fuerza. Paralelamente, sin embargo, en varios países existían coyunturas político-económicas críticas que requerían una rápida acción por parte de las autoridades en la toma de decisiones.

Este escenario era el propicio para la instauración de lo que Guillermo 0'Donnell denominaría como democracia delegativa, a partir de la emergencia de líderes que, en tanto "salvadores de la patria”, buscarían resolver los problemas existentes. ${ }^{13}$ Lo que evidenciaba esta situación era que los procesos transicionales desarrollados en la región en los años precedentes no siempre habían logrado consolidar o incluso desarrollar lo que él también va a conceptualizar como la segunda transición. Era este un desafío pendiente.

Comencemos por lo último, es decir, la relevancia de la segunda transición. Guillermo 0'Donnell demostró que el instaurar una democracia que pueda denominarse representativa requiere transitar dos transiciones y no sólo una. La primera es aquella que remite al proceso de salida del régimen anterior y la posterior instauración de un gobierno electo popularmente. La segunda se inicia con la presencia de dicho gobierno, y consiste en el desarrollo de un marco institucional respetado por todos los actores de cara al correcto funcionamiento del régimen. Es este paso lo que permitiría llegar a la poliarquía tal como la

\footnotetext{
12 O'Donnell, Guillermo, "Transiciones, continuidades y algunas paradojas", en Guillermo O'Donnell, Contrapuntos. Ensayos sobre autoritarismo y democratización, Buenos Aires, Legislatura Porteña de la Ciudad de Buenos Aires, 2014, p. 199.

${ }^{13}$ O'Donnell, Guillermo, "Nuevas reflexiones acerca de la democracia delegativa (DD)", en Guillermo O'Donnell, Osvaldo lazzetta y Hugo Quiroga (coords.), Democracia Delegativa, Buenos Aires, Prometeo, 2011, p. 25.
} 
entendió Robert Dahl. ${ }^{14}$ No obstante, el paso de la primera a la segunda transición no era automático, por lo que no había garantía de que el resultado final fuese el de una poliarquía, sino, tal vez, el de un tipo de democracia diferente.

Es el reconocimiento de estas dos transiciones lo que le permite a 0'Donnell plantear, en su ensayo "Transiciones, continuidades y algunas paradojas", dos objetivos diferentes (pero relacionados) que debían perseguirse una vez iniciada una transición: primero, evitar las regresiones; luego, fortalecer la democracia. Son dos aspectos independientes, pues alcanzar el primero no significaba cumplir con el segundo. Corolario: la segunda transición se transformaba en una tarea tan importante (e incluso dificultosa) como la primera. Esto llevaba a que fuese un desafío que, desde las nuevas democracias, se debía enfrentar en pos de su fortalecimiento. Frente a ello, la segunda transición implicaba una tarea fundamental: el diseño de un marco institucional que funcionase como un mecanismo de mediación entre los intereses existentes dentro de una comunidad. ${ }^{15}$

Dicho lo anterior, lo que inicialmente se había presentado como un desafío (la segunda transición), con posterioridad derivó en una desilusión con los resultados alcanzados en la región. Como se indica en la introducción del libro Democracia delegativa, la realidad encontrada en varias de las nuevas democracias generó un desencanto con el escenario postransicional, pues se identificaba la continuidad de viejos estilos de gobierno, incompatibles con la democracia esperada. ${ }^{16}$ En otras palabras, en estos casos la segunda transición no se había desarrollado adecuadamente. El descontento que surgía ante esta situación, cabe destacar, no eliminaba el desafío planteado con la segunda transición, sino que, al ser un resultado de la ausencia de su desarrollo, lo afirmaba como materia pendiente. Lo que sí quedaba en evidencia era que se estaba ante un escenario particular que debía explicarse. Las conceptualizaciones existentes de democracia no contaban con las herramientas para hacerlo, de acuerdo con la perspectiva de 0’Donnell. Así, democracias emergentes como las de Argentina, Brasil y Perú cumplían los criterios de la poliarquía de Dahl, pero eran de un tipo diferente al de la democracia representativa, es decir, aquella democracia donde los objetivos de la segunda transición estarían resueltos. Estas nuevas democracias eran particulares y, por tanto, había

\footnotetext{
${ }^{14}$ O'Donnell, Guillermo, "Transiciones, continuidades y algunas paradojas", Guillermo O'Donnell, Contrapuntos. Ensayos sobre autoritarismo y democratización, Buenos Aires, Legislatura Porteña de la Ciudad de Buenos Aires, 2014, p. 197. ${ }^{15}$ O'Donnell, Guillermo, "Transiciones, continuidades y algunas paradojas", en Guillermo O'Donnell, Contrapuntos. Ensayos sobre autoritarismo y democratización, Buenos Aires, Legislatura Porteña de la Ciudad de Buenos Aires, 2014, pp. 200 y 201.

${ }^{16}$ O'Donnell, Guilermo, Lazzetta, Osvaldo y Quiroga, Hugo, Democracia Delegativa, Buenos Aires, Prometeo, 2011, p. 9.
} 
que llamarlas de otra manera. Para tal efecto, O’Donnell adoptó el concepto de democracia delegativa. Esta última no parecía ser menos duradera que la democracia representativa (es decir, no contaba con una mayor amenaza de regresión autoritaria), pero sí involucraba una concepción particular del ejercicio del poder que era contraria a la encontrada en aquellas democracias que habian experimentado con mayor éxito una segunda transición, incluso en América Latina (como Chile y Uruguay). ${ }^{17}$

La pregunta que surge es ¿por qué 0’Donnell habló de una concepción particular del ejercicio del poder en una democracia delegativa? Lo hizo porque en estos regímenes se apreciaba que aquel que ganase la elección presidencial lo hacía suponiendo que tendría el derecho a gobernar como él o ella lo considerara adecuado, sin otros limitantes para dicha discrecionalidad que el periodo de gobierno previamente estipulado y las relaciones de poder entre los actores políticos. ${ }^{18}$ Esto suponía ubicar al presidente en una posición superior al resto de los actores (ciudadanos y políticos) e instituciones por ser la figura que, bajo la interpretación de su rol en una democracia delegativa, se transformaba en la "encarnación de la nación"; por tanto, debía interpretar y ejecutar los verdaderos intereses de su país, independientemente de las promesas efectuadas durante la campaña electoral.

0'Donnell se pregunta si "acaso no fue el presidente autorizado a gobernar como él creía mejor". ${ }^{19} \mathrm{Al}$ actuar de esta manera, el presidente parecería quedar libre de dar explicaciones sobre sus acciones tanto a los votantes como a los actores de la arena institucional. Como consecuencia, aparece en su esencia la debilidad alcanzada por la segunda transición en los casos delegativos, debido a que las instituciones (como las pertenecientes al poder legislativo y al judicial) y los actores en ellas pasaban a ser vistos como estorbos para el accionar presidencial.

Paralelamente, para 0’Donnell el concepto de poliarquía hacía silencio sobre la importancia del grado de rendición de cuentas de los gobiernos en función de sus acciones. ${ }^{20}$ Esta situación para él era clave. Por ello, evaluó tal concepto a partir de la noción de rendición de cuentas (accountability), la cual se divide en dos tipos: vertical y horizontal. Mientras que la primera remite a la rendición de cuentas periódica frente a la ciudadanía (presente en la democracia representativa y en la delegativa), la segunda refiere al control institucional,

\footnotetext{
${ }^{17}$ O'Donnell, Guillermo, "Democracia delegativa", Journal of Democracy en Español 8.1, pp. 16 y 17.

${ }^{18}$ O'DonnelL, Guillermo, "Democracia delegativa", Journal of Democracy en Español 8.1, p. 12.

${ }^{19}$ O'Donnell, Guillermo, "¿Democracia delegativa?", en Guillermo O'Donnell, Contrapuntos. Ensayos sobre autoritarismo y democratización, Buenos Aires, Legislatura Porteña de la Ciudad de Buenos Aires, 2014, p. 267.

${ }^{20}$ O'Donnell, Guillermo, "Illusions about Consolidation", Journal of Democracy 7.2, 1996, p. 35.
} 
fundamentalmente basado en la división de poderes (ausente o muy débil en la democracia delegativa). ${ }^{21}$ Como resultado, en una democracia delegativa la ausencia de una adecuada rendición de cuentas horizontal permitiría al presidente electo popularmente concentrar en su figura las decisiones de una manera rápida pero carente de control.

Nótese que el inadecuado funcionamiento de la rendición de cuentas horizontal no significaba la ausencia formal de las instituciones involucradas. Estas últimas existen, pero no funcionan bien. Si esto lo relacionamos con el hecho de que las democracias delegativas podían no ser transitorias sino duraderas, las prácticas plebiscitarias que 0’Donnell identificó en estos escenarios podían transformarse en la regla, a pesar de que la ley plantease un funcionamiento diferente. Esto significaba, desde la lectura de 0’Donnell, que las democracias delegativas no carecían de institucionalización; la tenían, pero era diversa a la encontrada en las democracias representativas. Mientras que en estas últimas existía una institucionalización formal basada en el respeto de un entramado explícitamente formalizado de reglas, en las democracias delegativas primaba una institucionalización informal alejada de las palabras escritas en las normas y centrada en el particularismo y la discrecionalidad. ${ }^{22}$ Las consecuencias negativas de esta situación eran evidentes: "Una es que la falta generalizada de controles protege y realimenta viejas prácticas autoritarias. La otra es que se introducen fuertes sesgos, en términos de influencia sobre la elaboración e implementación de políticas, a favor de los intereses altamente organizados y económicamente poderosos, en países que inauguraron sus poliarquías en condiciones de aguda desigualdad". ${ }^{23}$

Podríamos decir entonces que al presentar la democracia delegativa, 0'Donnell estaba llevando adelante lo que él denominó como una crítica democrática de la democracia, al señalar los obstáculos y acciones que dificultaban el funcionamiento de este tipo de régimen. ${ }^{24}$ Frente a ello, el legado de este concepto se encuentra en dos grandes aspectos. Por un lado, evidenció que detrás de la visión plebiscitaria del ejercicio del poder se encontraba una marginalización del marco institucional que podría actuar como un freno y

\footnotetext{
${ }^{21}$ O'Donnell, Guillermo, "¿Democracia delegativa?", en Guillermo O'Donnell, Contrapuntos. Ensayos sobre autoritarismo y democratización, Buenos Aires, Legislatura Porteña de la Ciudad de Buenos Aires, 2014, p. 270.

${ }^{22}$ O'Donnell, Guillermo, "Otra institucionalización", Guillermo O'Donnell, Contrapuntos. Ensayos sobre autoritarismo y democratización, Buenos Aires, Legislatura Porteña de la Ciudad de Buenos Aires, 2014, p. 298.

${ }^{23}$ O'Donnell, Guilermo, "Otra institucionalización", Guillermo O'Donnell, Contrapuntos. Ensayos sobre autoritarismo y democratización, Buenos Aires, Legislatura Porteña de la Ciudad de Buenos Aires, 2014, p. 301.

${ }^{24}$ O'Donnell, Guillermo, "Transiciones, continuidades y algunas paradojas", Guillermo O'Donnell, Contrapuntos. Ensayos sobre autoritarismo y democratización, Buenos Aires, Legislatura Porteña de la Ciudad de Buenos Aires, 2014, p. 196.
} 
contrapeso frente al proceso decisional. Por otro, su aporte le planteó a los casos con democracias delegativas el carácter pendiente del desafío de la segunda transición. El futuro de estas democracias estaba entonces entre sostener el statu quo delegativo o hacer la segunda transición que les permitiese transformar sus democracias en representativas.

\section{Tercer desafío: del RÉGimen al Estado demOcrático}

El tercer desafío que aquí presentaremos sigue una lógica similar al anterior, pues también requirió un refinamiento conceptual producto de un vacío no contemplado por la literatura existente. El aporte de Guillermo O'Donnell, y el consiguiente desafío que de este surgió, tiene el mismo origen que el visto en la sección precedente: la comparación. Nuevamente, las conceptualizaciones tradicionales, si bien eran realistas, no eran del todo compatibles con la realidad encontrada en las nuevas democracias, pues estas últimas tenían características particulares no contempladas por las primeras. Este hecho requería de una teorización. Guillermo 0'Donnell planteó la necesidad de un refinamiento conceptual en el sentido de que una cosa era el régimen democrático y otra el Estado democrático. Las definiciones tradicionales, de acuerdo con nuestro autor, se centraban en el primer aspecto pero no cubrían las características del segundo. El problema con esta situación lo comienza a plantear de la siguiente manera en su libro Disonancias:

El argumento que desarrollaré aquí es que existe una estrecha conexión de la democracia con ciertos aspectos de la igualdad entre individuos que se posicionan no meramente como individuos sino como "personas legales”, y en consecuencia como ciudadanos/as, es decir, como portadoras de derechos y obligaciones que derivan de su pertenencia a un demos, una comunidad política y del hecho de que se les atribuye agencia personal y, por lo tanto, responsabilidad por sus acciones. ${ }^{25}$

Como veremos aquí, no es desde el análisis del régimen que puede evaluarse el carácter legal de las personas, sino desde el Estado, dos dimensiones que pueden desarrollarse de manera diferente. Por lo tanto, si puede hablarse de la existencia o no de un régimen democrático, también puede hacerse lo mismo en lo referente a la presencia o no de un Estado democrático.

\footnotetext{
25 O'Donnell, Guillermo, Disonancias. Críticas democráticas a la democracia, Buenos Aires, Prometeo, 2007, pp. 153 y 154.
} 
Incorporar al Estado dentro de la órbita del análisis democrático llevó a Guillermo 0'Donnell a presentar una idea que se transformó en un aspecto esencial para su argumento, la cual es que los individuos en democracia no sólo son actores que pueden votar y aspirar a ocupar cargos públicos, sino que además de eso, son sujetos de derecho. A partir de ello, unos y otros, el ego y el alter, son iguales entre sí, independientemente de sus visiones del mundo o condiciones sociales y económicas. Tal igualdad debe encontrar en la ley la garantía de su existencia. Esto tiene sus implicancias para el funcionamiento de la democracia.

El Estado tiene un rol esencial en lo anterior, pues es a partir del mismo que se expresa el sistema legal dentro de un territorio delimitado y, por tanto, es el articulador y organizador de la sociedad. ${ }^{26}$ Para cumplir con dicho rol, O'Donnell destaca que el sistema legal es una dimensión constitutiva del Estado, ya que es mediante las leyes y normativas en general que el anterior busca imponer su autoridad y así mediar en las relaciones sociales. ${ }^{27}$ Como resultado, un Estado efectivo es aquel que logra construir una red de instituciones que ponen en funcionamiento efectivo las obligaciones, los derechos y las garantías provenientes del sistema legal. Debe ocurrir esto entre toda la población (los agentes) y a lo largo de todo un territorio. Funcionando de tal manera es que un Estado se transforma en un "estado-para-la-nación", e impulsa la generación de una identidad colectiva representada en la idea de un "nosotros". ${ }^{28}$

La ley debe ser también la garantía frente al abuso de poder, por ejemplo, en lo que refiere a la relación gobernante-gobernado. Es la ley la que establece las obligaciones, los derechos y las garantías que tienen aquellos que están en el poder (gobernantes) y aquellos que se encuentran bajo las directivas establecidas por los primeros (gobernados). Por lo tanto, los que gobiernan dominan, pero no deben hacer un uso abusivo de su poder. Es a partir de la ley que se imponen los límites de dicha acción. Sólo cuando en la práctica ocurre lo hasta aquí mencionado, es que 0'Donnell plantea que a los individuos se los puede considerar como ciudadanos, ya que no sólo pueden votar, sino que además cuentan con un sistema legal que a nivel universal les permite disfrutar

\footnotetext{
${ }^{26}$ O'Donnell, Guillermo, "Apuntes para una teoría del estado", en Guillermo O'Donnell, Catacumbas, Buenos Aires, Prometeo, 2008, p. 230.

${ }^{27}$ O'Donnell, Guillermo, "Acerca del Estado, la democratización y algunos problemas conceptuales. Una perspectiva latinoamericana con referencias a paises poscomunistas", en Guillermo O'Donnell, Contrapuntos. Ensayos sobre autoritarismo y democratización, Buenos Aires, Legislatura Porteña de la Ciudad de Buenos Aires, 2014, p. 237. ${ }^{28}$ O'Donnell, Guillermo, Democracia, agencia y estado. Teoría con intención comparativa, Buenos Aires, Prometeo, 2010, p. 79.
} 
de derechos y garantías. ${ }^{29}$ No obstante, cabe destacar que 0’Donnell no limita las consecuencias de las relaciones de poder a una cuestión política, sino que puede encontrarse en las diferentes arenas de interacción social. 0'Donnell lo plantea así:

Aún en las instancias aparentemente más privadas del derecho, el sistema legal incorpora la dimensión pública originada por la remisión virtual de esa relación para su tratamiento en manos de un organismo competente del estado. Esta dimensión intrínsecamente pública de las relaciones privadas (o sea, esta texturización de esas relaciones por el estado-en-tanto-ley) es violada cuando, por ejemplo, a un campesino se le niega de facto el acceso a los tribunales para pleitear contra un terrateniente. Este derecho "privado" no debe considerarse menos constitutivo de la ciudadanía que el derecho "público" de votar sin coacción. ${ }^{30}$

De esta manera el impacto de la ley no se limita a la relación gobernantegobernado, sino que involucra a todos los individuos que viven y conviven en una comunidad. Nadie puede actuar como un legibus solutus. ${ }^{31}$

Teniendo en cuenta todo lo dicho hasta aquí, la pregunta que surge es ¿por qué a O’Donnell le resultó muy importante el destacar las características del Estado, del sistema legal y su relación con la democracia? La respuesta está en que, de acuerdo con su perspectiva, en muchas de las nuevas democracias, la existencia de elecciones limpias ha coexistido con una escasa efectividad de los derechos (ya sea en el carácter universal como geográfico de su implementación). Por lo tanto, había que diferenciar a los países donde se respetaban los derechos de aquellos donde eso no ocurría de manera efectiva a pesar de la existencia formal pero no sustantiva del sistema legal. Había que diferenciarlos pues si bien podría decirse que ambos grupos de países contaban con regímenes democráticos, el funcionamiento de los mismos podría ser diferente producto de la dispar vigencia del sistema legal.

En términos del impacto del inadecuado funcionamiento del sistema legal, O’Donnell es tajante. Sostiene que, si bien tanto en las democracias del

\footnotetext{
${ }^{29}$ O'Donnell, Guillermo, Democracia, agencia y estado. Teoría con intención comparativa, Buenos Aires, Prometeo, 2010, p. 89.

${ }^{30}$ O'Donnell, Guillermo, "Acerca del Estado, la democratización y algunos problemas conceptuales. Una perspectiva latinoamericana con referencias a paises poscomunistas", en Guillermo O'Donnell, Contrapuntos. Ensayos sobre autoritarismo y democratización, Buenos Aires, Legislatura Porteña de la Ciudad de Buenos Aires, 2014, p. 239. ${ }_{31}^{31}$ O'Donnell, Guilermo, Disonancias. Críticas democráticas a la democracia, Buenos Aires, Prometeo, 2007, p. 73.
} 
noroeste como en las más nuevas existían elecciones limpias e institucionalizadas, paralelamente se generaban situaciones críticas, raras en las primeras pero más comunes en las segundas. En estas últimas:

No rigen otras importantes libertades y garantías, incluidas las que forman parte del repertorio clásico de los derechos civiles. Me refiero a situaciones en las que las mujeres o diversos grupos minoritarios son discriminados aunque el texto de la ley lo prohíba; en que se niega, de jure o de facto, el derecho de sindicalización a trabajadores o campesinos; en que la policía y varios grupos mafiosos violan recurrentemente derechos de los pobres de grupos discriminados; en que el acceso a la justicia es muy sesgado, etc. Estos grupos gozan -si es que el caso en cuestión califica verdaderamente como un régimen democrático- de los derechos políticos que corresponden al régimen, pero sus derechos civiles están severamente menoscabados. ${ }^{32}$

La ineficiencia a la que alude 0'Donnell no se limitaba al carácter sesgado de la implementación del sistema legal. El autor no deja de prestar atención al carácter territorial de las instituciones estatales. Es por ello que un Estado ineficiente también es aquel que no tiene la capacidad de asegurar el funcionamiento de su sistema legal dentro de la totalidad de su territorio. Ahora bien, la (in)efectividad estatal puede a nivel territorial no ser total, sino tener una distribución geográfica heterogénea. Esto significa que en algunas regiones de un mismo país el Estado puede funcionar de manera adecuada y en otras no. Así, la heterogeneidad geográfica de la (in)efectividad estatal encontró en O'Donnell una forma de ser plasmada conceptualmente con las llamadas "zonas de colores".

Imaginemos un mapa de cada país donde las zonas color azul señalan un alto grado de presencia del estado, tanto en el aspecto funcional como territorial (es decir, un conjunto de burocracias razonablemente eficaces y la existencia de una legalidad efectiva); las verdes indican un alto grado de penetración territorial y una presencia mucho menor en términos funcionales, y las marrones significan un nivel muy bajo o nulo de ambas dimensiones. ${ }^{33}$

\footnotetext{
${ }^{32}$ O'Donnell, Guillermo, Disonancias. Críticas democráticas a la democracia, Buenos Aires, Prometeo, 2007, pp. 76 y 77. ${ }^{33}$ O'Donnell, Guillermo, "Acerca del Estado, la democratización y algunos problemas conceptuales. Una perspectiva latinoamericana con referencias a paises poscomunistas", en Guillermo O'Donnell, Contrapuntos. Ensayos sobre autoritarismo y democratización, Buenos Aires, Legislatura Porteña de la Ciudad de Buenos Aires, 2014, p. 243.
} 
En los países donde existe heterogeneidad territorial estatal, 0'Donnell demuestra que usualmente el color azul tiende a encontrarse en los grandes centros urbanos, mientras que en las zonas periféricas es donde el marrón tiende a primar y, por ende, donde el carácter universal de la ley se pierde y el particularismo es la regla.

De este modo, de existir escenarios donde la inefectividad quiebra el universalismo del sistema legal, donde la agencia no se encuentra y por ende la igualdad legal entre los individuos tampoco, la conclusión de 0'Donnell es clara y certera: la etiqueta de "democrático" y "autoritario" puede no corresponder sólo al régimen sino también al Estado. Esto último tiene dos grandes derivaciones. Por un lado, son estos los escenarios que los líderes con tendencia autoritaria (que pueden haber sido electos mediante elecciones competitivas) encuentran con una ventana de oportunidades para imponer su poder discrecional. Por otro, al no contar con su sustento legal, la ciudadanía se debilita y se impone lo que 0’Donnell denomina como una ciudadanía de baja intensidad, la cual se caracteriza por disfrutar adecuadamente de los derechos políticos propios de la participación en las elecciones e indicadas por la poliarquía, pero al mismo tiempo, por experimentar abusos de poder y una marginalización en el acceso a la justicia o el disfrute de derechos sociales. Así, los individuos dejan de ser ciudadanos plenos para ser únicamente súbditos sometidos a relaciones autoritarias y alejadas de las reglas establecidas por el sistema legal. ${ }^{34}$

En sus últimos libros, como Disonancias o Democracia, agencia y estado, 0’Donnell no sólo se encargó de presentar la teoría, también se encargó de demostrar que la situación presentada en términos teóricos era la que se encontraba en América Latina. Evidenciar esta situación crítica ha sido, creemos, el último gran aporte de 0’Donnell a la democracia en América Latina, pues presentó un último desafío: transitar el camino hacia un Estado democrático, hecho que en la región aún se encuentra pendiente.

\section{Conclusiones: el legado de Guillermo O’Donnell}

El objetivo de este trabajo ha sido discutir el aporte que Guillermo 0'Donnell le ha legado a la democracia en las últimas décadas. Su obra ha significado descripción, explicación y presentación de desafíos. Así, las páginas que redactó, consumidas por generaciones de lectores, han puesto en interacción la teoría

\footnotetext{
${ }^{34}$ O'Donnell, Guillermo, Democracia, agencia y estado. Teoría con intención comparativa, Buenos Aires, Prometeo, 2010, p. 89.
} 
con un aspecto más normativo de hacia donde deberían dirigirse los "tipos" de democracia en América Latina en pos de transformarse en mejores versiones de sí mismas.

Las tres líneas de análisis que nosotros hemos decidido presentar dan cuenta de esta interacción entre la teoría y el carácter normativo de la obra de Guillermo 0'Donnell. Indagar, durante y con posterioridad al contexto de la tercera ola de democratización, sobre las trayectorias transicionales y sobre el "real" funcionamiento de las democracias emergentes, le permitió a nuestro autor encarar diferentes etapas de una agenda de investigación donde hemos podido identificar tres grandes aspectos. Primero, la construcción e introducción de teoría democrática sostenida en conceptualizaciones novedosas que han perdurado hasta la actualidad. Segundo, al demostrar mediante su teoría la particularidad de las democracias emergentes respecto a aquellas con un mayor rodaje histórico e institucional, 0'Donnell puso sobre la mesa de debate las limitaciones que las definiciones tradicionales de democracia tenían para dar cuenta de la realidad encontrada en las primeras. Tercero, las particularidades no se presentaron como virtudes sino como falencias que debían resolverse de cara a la construcción de democracias representativas e institucionalizadas. De ahí, los tres desafíos que en estas páginas hemos analizado: de lo macro a lo micro; de la primera a la segunda transición; del régimen al Estado democrático. Este ha sido el legado que 0'Donnell le ha dejado al estudio de la democracia en América Latina.

La ciencia política, como toda disciplina científica, es acumulable; sigue avanzando después del paso de los grandes intelectuales que dejan su marca. Ellos, a partir de su obra, dejan lecciones a las que aquellos que venimos después acudimos para estudiar e investigar. Hoy no puede hablarse de democracia sin remitirse a la obra de Joseph Schumpeter, Samuel Huntington, Adam Przeworski o Robert Dahl. Hoy no puede hablarse de democracia en América Latina sin citar la obra de Guillermo 0’Donnell.

BiBliografía

DAHL, RoBert, La democracia y sus críticos, Paidós, Buenos Aires, 1992.

DAHL, ROBERT, "La poliarquía”, en Varios autores, Diez textos básicos de ciencia política, Barcelona, Ariel, 2007.

O’Donnell, Guillermo, "Illusions about Consolidation”, Journal of Democracy 7.2, 1996.

O’Donnell, Guilermo, Disonancias. Críticas democráticas a la democracia, Buenos Aires, Prometeo, 2007. 
O’Donnell, Guillermo, “Tensiones en el Estado burocrático-autoritario y la cuestión de la democracia”, en Guillermo 0’Donnell, Catacumbas, Buenos Aires, Prometeo, 2008.

O’Donnell, Guillermo, "Notas para el estudio de procesos de democratización política a partir del Estado burocrático-autoritario”, Guillermo 0’Donnell Contrapuntos. Ensayos sobre autoritarismo y democratización, Buenos Aires, Legislatura Porteña de la Ciudad de Buenos Aires, 2014.

O’Donnell, Guilermo, “Apuntes para una teoría del Estado”, en Guillermo 0’Donnell, Catacumbas, Buenos Aires, Prometeo, 2008.

O’Donnell, Gulllermo, “Democracia delegativa”, Journal of Democracy en Español 8.1. O’Donnell, Gullermo, Democracia, agencia y estado. Teoría con intención comparativa, Buenos Aires, Prometeo, 2010.

O’Donnell, Guillermo, “Democracia en la Argentina. Micro y macro”, en Guillermo O’Donnell, Contrapuntos. Ensayos sobre autoritarismo y democratización, Buenos Aires, Legislatura Porteña de la Ciudad de Buenos Aires, 2014.

O’Donnell, Guillermo, “¿Y a mí, qué mierda me importa? Notas sobre sociabilidad y política en la Argentina y Brasil”, en Guillermo O’Donnell, Contrapuntos. Ensayos sobre autoritarismo y democratización, Buenos Aires, Legislatura Porteña de la Ciudad de Buenos Aires, 2014.

O’Donnell, Guillermo, “Transiciones, continuidades y algunas paradojas”, Guillermo O’Donnell, Contrapuntos. Ensayos sobre autoritarismo y democratización, Buenos Aires, Legislatura Porteña de la Ciudad de Buenos Aires, 2014.

O’Donnell, Guillermo, “Acerca del Estado, la democratización y algunos problemas conceptuales. Una perspectiva latinoamericana con referencias a países poscomunistas”, en Guillermo 0'Donnell, Contrapuntos. Ensayos sobre autoritarismo y democratización, Buenos Aires, Legislatura Porteña de la Ciudad de Buenos Aires, 2014.

O’Donnell, Guillermo, “¿Democracia delegativa?”, en Guillermo O’Donnell, Contrapuntos. Ensayos sobre autoritarismo y democratización, Buenos Aires, Legislatura Porteña de la Ciudad de Buenos Aires, 2014.

O’Donnell, Guillermo, “Otra institucionalización”, en Guillermo O’Donnell, Contrapuntos. Ensayos sobre autoritarismo y democratización, Buenos Aires, Legislatura Porteña de la Ciudad de Buenos Aires, 2014.

O’Donnell, Guillermo y Schmitter, Philippe, Transiciones desde un gobierno autoritario. Conclusiones tentativas sobre las democracias inciertas, Buenos Aires, Prometeo, 2010.

O’Donnell, Guillermo, "Nuevas reflexiones acerca de la democracia delegativa (DD)”, en Guillermo O’Donnell, Osvaldo Iazzetta, Osvaldo y Hugo Quiroga (coords.), Democracia Delegativa, Buenos Aires, Prometeo, 2011.

O’Donnell, Guilermo, Iazzetta, Osvaldo y Quiroga, Hugo, Democracia Delegativa, Buenos Aires, Prometeo, 2011. 
Przenorski, Adam, Democracy and the Market. Political and Economic Reforms in Eastern Europe and Latin America, Nueva York, Cambridge University Press, 1991.

Schumpeter, Joseph, Capitalism, Socialism, and Democracy, Nueva York, Harper, 1975. 